\title{
Experimental and Numerical Research on Cylindrical Tubes under Outer Cylindrical Explosive Waves
}

\author{
Sui Yaguang, ${ }^{1,2}$ Zhang Dezhi, ${ }^{2}$ Tang Shiying, ${ }^{2}$ and Chen $\mathrm{Bo}^{2}$ \\ ${ }^{1}$ State Key Laboratory for Disaster Prevention \& Mitigation of Explosion \& Impact, PLA University of Science and Technology, \\ Nanjing 210007, China \\ ${ }^{2}$ Key Laboratory of Intense Dynamic Loading and Effect, Northwest Institute of Nuclear Technology, Xian 710024, China
}

Correspondence should be addressed to Sui Yaguang; suiyaguang@nint.ac.cn

Received 5 January 2017; Revised 29 March 2017; Accepted 9 April 2017; Published 4 June 2017

Academic Editor: Evgeny Petrov

Copyright (C) 2017 Sui Yaguang et al. This is an open access article distributed under the Creative Commons Attribution License, which permits unrestricted use, distribution, and reproduction in any medium, provided the original work is properly cited.

\begin{abstract}
Cylindrical explosive loading has an important application in explosive working, researching on weapon damage, and explosivedriving load. This study uses experimental and numerical methods to study the response of long and thin tubes when subjected to cylindrical explosive loading. The flake-like charge and multipoint initiation technique were adopted to load cylindrical explosive waves. Experimental results showed that the method could produce uniform deformation in certain parts of the long tube, but partial spall injuries occurred after the explosion. The macroscopic and microscopic deformation of tubes were analyzed. Numerical simulations were conducted to investigate the detailed response of the tube subjected to a cylindrical explosive wave. The results indicate that the collision of explosive waves brought inconsistencies in pressure and velocity. The pressure and velocity in the collision region were significantly higher than those of other parts, which caused the collision region to be easily damaged.
\end{abstract}

\section{Introduction}

Converging cylindrical shock waves have been widely applied in explosive working, research on weapon damage, and the driving load in special occasions [1-5]. J. H. Lee and B. H. K. Lee [1] developed a technique for producing imploding cylindrical shock waves through imploding detonation waves. Matsuo [2] investigated the converging shock wave generated by instantaneous energy release over cylindrical surface. Wu et al. [3] introduced an improved experimental technique for the production of cylindrical converging shock waves. Apazidis et al. [4] studied converging polygonal shock waves using experimental and theoretical analysis method. Krasik, Grinenko, and Sayapin produced a sub-Mbr pressure on the axis of the implosion wave by an underwater electrical explosion of a cylindrical wire array.

Explosive energy has been widely used in industrial production and military. If dispersive charges symmetrically disposed on the exterior of a cylindrical tube were detonated at the same time, they will bring an approximate converging cylindrical explosive wave. The cylindrical tube was found to have shrunk under cylindrical explosive. The research on the dynamic response of a cylindrical tube loaded by a cylindrical explosive wave is an important reference to parallel studies. The effect on the cylindrical tube is directly related to the energy of the cylindrical explosive wave. If the energy is minimal, the tubes will only have an elastic deformation or a small plastic deformation. If the explosive energy is strong, the tube will shrink significantly and may spall [6-9] and even break up [10-12]. The methods of installation and detonation of charges directly affect the outcome on tubes too. Cylindrical charges must be detonated simultaneously to obtain cylindrical explosive waves. This condition is difficult to implement in practice; thus, approximate methods were developed. One method is to completely cover the experimental cylinder with explosives. A conical detonation charge is connected to one end of the cylinder. After the prick point is detonated, a cylindrical explosive wave will spread along the axial direction of the cylinder. This method could produce a standard load, though the introduction of the conical charge may influence the loading precision. Xuemei [13] studied the spall characteristics of cylindrical 
steel tube using the method. The other method is the multipoint initiation technique, which sets multi-initiation points and observes simultaneous detonation on the annulus of cylindrical charges [14-16]. This method produces a high pressure and temperature from the inconsistent rounding load and the collision of explosive waves in the mid-line between two nearby initiation points. The inconsistency may lead to a range of results on the experimental specimen. Terao et al. [14] investigated cylindrical detonation wave formed by the multipoint initiation method. Mochalova and Utkin [16] proposed a mathematical modeling based on the latest experimental data to study the cylindrical detonation process and gas dynamics of the explosion products. The numerical simulation of converging cylindrical detonation waves at multipoint initiation for the recent experiments in IPSP RAS was conducted.

For certain special applications in explosive works, the tubes only need a small shrinkage deformation in a certain section without causing serious damage; this condition indicates the need for precise explosive loading. In the studies above, the liquid charge, plastic charge, or powdery charge was used. The liquid charge and plastic charge were insensitive charges, which have large explosive critical diameters. When the thickness of the charge is too thin, charge detonation is difficult to achieve. The liquid charge and plastic charges used to be detonated by the electric detonator, which would bring fragments and a jet load. These charges were unsuitable for achieving an accurate load. The powder charge can be used for certain complicated structures; however, the process of filling and compaction is dangerous. Flake-like charges could steadily detonate when the thickness is at least $0.1 \mathrm{~mm}$ and pliable enough to adapt to various figures. Flakelike charges can be applied in high-precision loading for specially shaped specimens [17].

This study applied experimental and numerical research methods to develop a technique that could obtain a feasible deformation in the middle section of a long cylindrical tube. Two kinds of flake-like charges, PTEN with a thickness of $0.5 \mathrm{~mm}$ and RDX with a thickness of $2.5 \mathrm{~mm}$, and the multipoint initiation technique were adopted to load the cylindrical explosion. One experiment was carried out to observe the macroscopic and microcosmic characteristics of tubes. Numerical simulations were performed to investigate the distribution of pressure, velocity, deformation, and dynamic fracture.

\section{Experiment}

2.1. Experimental Setup. Figure 1 depicts the experimental model that consists of a cylindrical tube with two open ends, a flake-like charge, the plank, and a multipoint initiation net. The material of the tube was 20\# steel with an inner diameter of $100 \mathrm{~mm}$, thickness of $12 \mathrm{~mm}$, and length of $600 \mathrm{~mm}$. The tube was fixed on the plank. The flake-like charges were symmetrically disposed on the exterior of the tube. The multipoint initiation net consisted of mild detonating fuses, a detonating charge, and an electric detonator. One end of detonating fuses, namely, initiation points, was distributed uniformly on the middle annulus of the flake-like charge. The

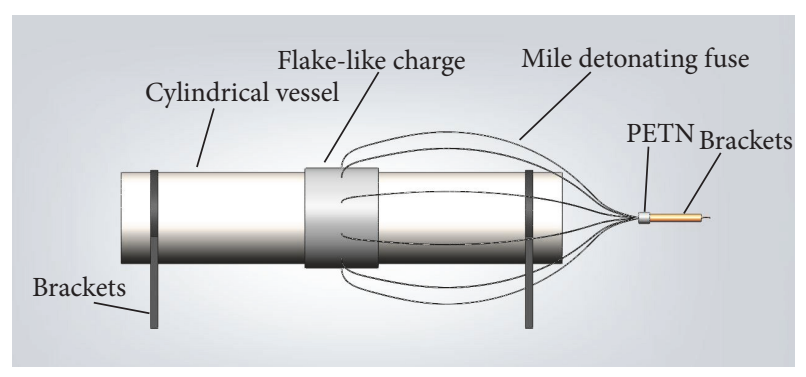

FIGURE 1: Experiment mode.

TABle 1: Parameters of charges.

\begin{tabular}{cccc}
\hline Number & $\begin{array}{c}\text { Thickness of } \\
\text { flake-like } \\
\text { charges }\end{array}$ & $\begin{array}{c}\text { Length of } \\
\text { flake-like } \\
\text { charges }\end{array}$ & $\begin{array}{c}\text { Number of } \\
\text { initiation points }\end{array}$ \\
\hline PETN $(0.5 \mathrm{~mm})$ & & 10 \\
+ RDX $(2 \times$ & $100 \mathrm{~mm}$ & \\
$2.5 \mathrm{~mm})$ & & \\
\hline
\end{tabular}

other end of detonating fuses was initiated by an electric detonator. To ensure dependability a piece of detonating charge of PETN was disposed between the electric detonator and the detonating fuses, which were of the same length. The flakelike charge could be initiated simultaneously. More initiation points were correlated with a better load consistency.

The flake-like charges and detonating fuses were shown in Figure 2(a). Figure 2(b) shows the detonation sequence of flake-like charges. PETN overlain on RDX was used to obtain the required thickness. The PETN charge was detonated by the more sensitive detonating core, whereas the RDX charge was detonated by the PETN. The detonating fuse had a diameter of $1 \mathrm{~mm}$ and a line charge density of $0.5 \mathrm{mg}(\mathrm{RDX}) / \mathrm{mm}$.

Table 1 shows the details of charges. PETN thickness was at $0.5 \mathrm{~mm}$, and RDX was at $5 \mathrm{~mm}$. Ten initiation points were distributed uniformly on the middle annulus of flake-like charges.

The electric probe is the common method to measure the reach time of the explosive waves, because its response time is less than $1 \mathrm{~ns}$. In this study, electric probes were used to investigate the synchronization of the detonation net. Four probes were, respectively, assigned near four initiation points, as shown in Figure 3(a). The probes were made of two enameled copper wires with a $0.1 \mathrm{~mm}$ diameter. Figure $3(\mathrm{~b})$ shows the state of the experiment after the installment.

\subsection{Experimental Results and Analysis}

2.2.1. Synchronization of Initiation. The signal of the electric probes was shown in Figure 4. The maximum time difference was $1 \mu \mathrm{s}$, indicating that the detonating net had good synchronization.

2.2.2. Deformation. Figure 5 shows the state of the tube after the explosion, whereas Figure 6 shows the deformation of the axis direction. Assume that the cylindrical core was the 


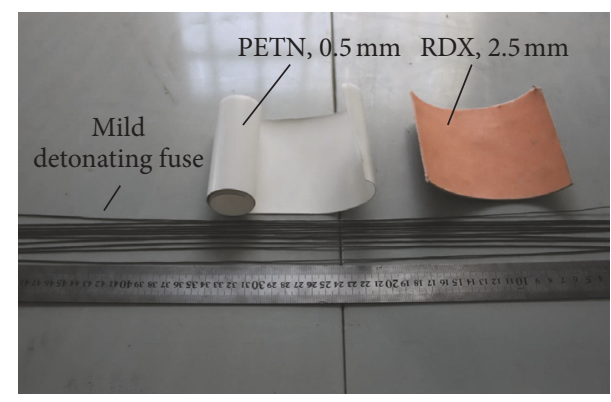

(a)

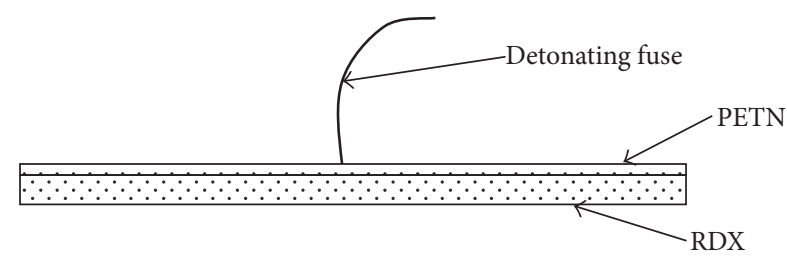

(b)

FIgURE 2: Flake-like charges and detonation cores.

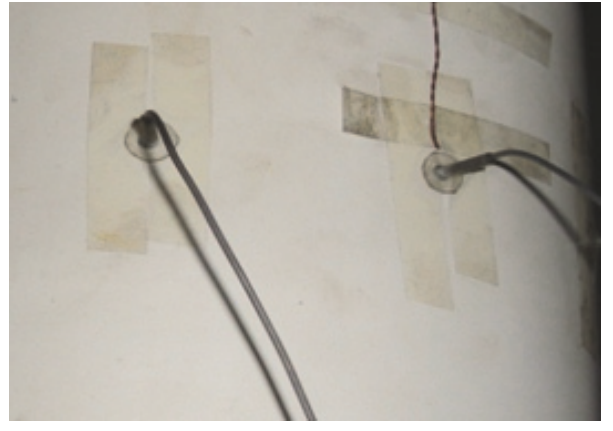

(a) Initiation point and electric probe

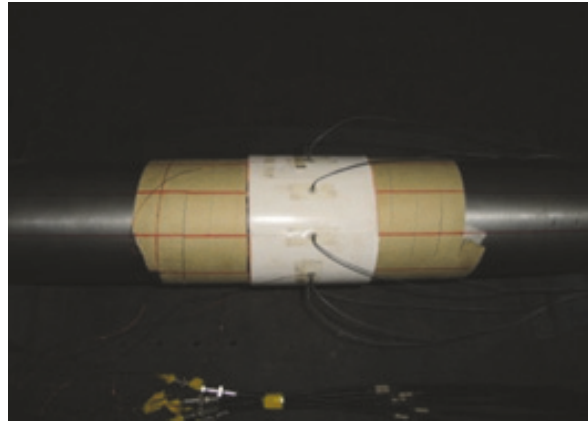

(b) The state after installment

Figure 3: Photos of experiment.

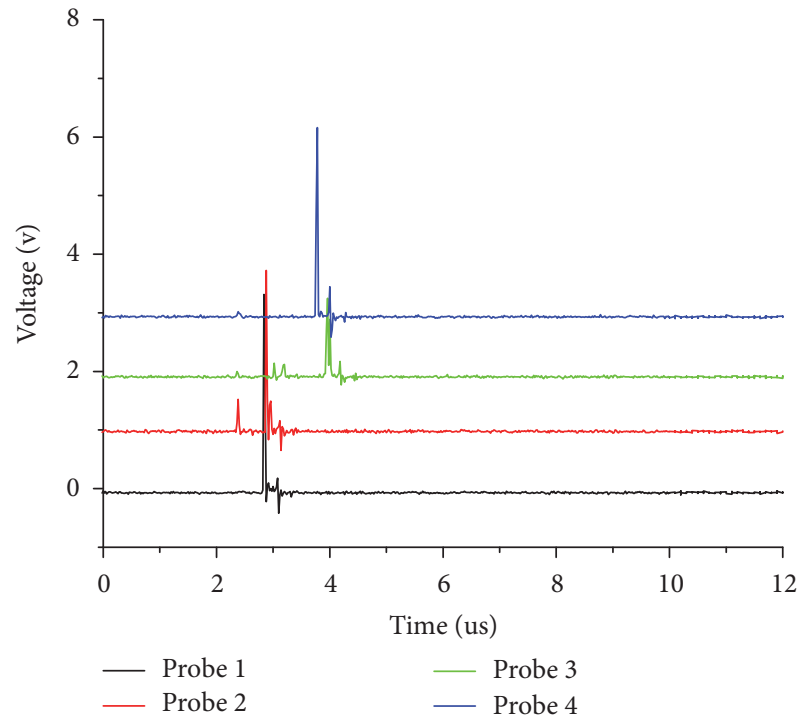

FIGURE 4: Signal of electric probes.

origin, the axis was $x$-axis, the radial direction was $y$-axis, and the deformation direction was positive direction. Five positions were selected, and the maximum difference was approximately $0.7 \mathrm{~mm}$. The deformation was centralized in the explosive region, indicating a high loading precision. The maximum value was approximately $5.8 \mathrm{~mm}$ in the center of

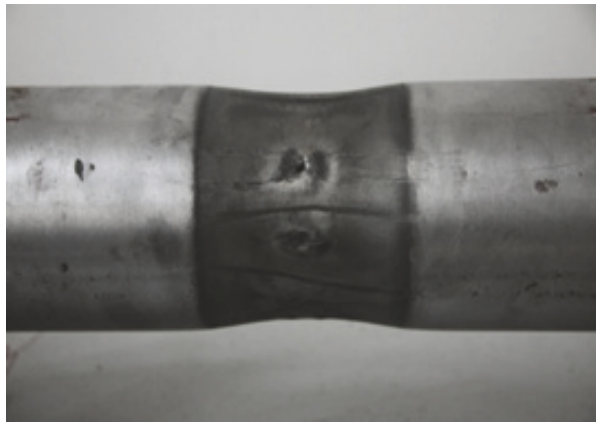

Figure 5: State of the tube after explosion.

the explosive region. A $40 \mathrm{~mm}$ long, approximately flat region was noted.

2.2.3. Damage. The tube shrunk after the explosion, and an oxygen layer was formed by the high temperature, as shown in Figure 5. A punctiform scar on each initiation point and a line scar between the neighboring points existed in the explosive region. The punctiform scars were formed by the detonating fuses. The line scars were formed by the collision of explosive waves from neighboring initiation points. After initiation, the explosion waves spread out in a constant velocity from each detonation point and then met at the midcourt line between two neighboring detonation 


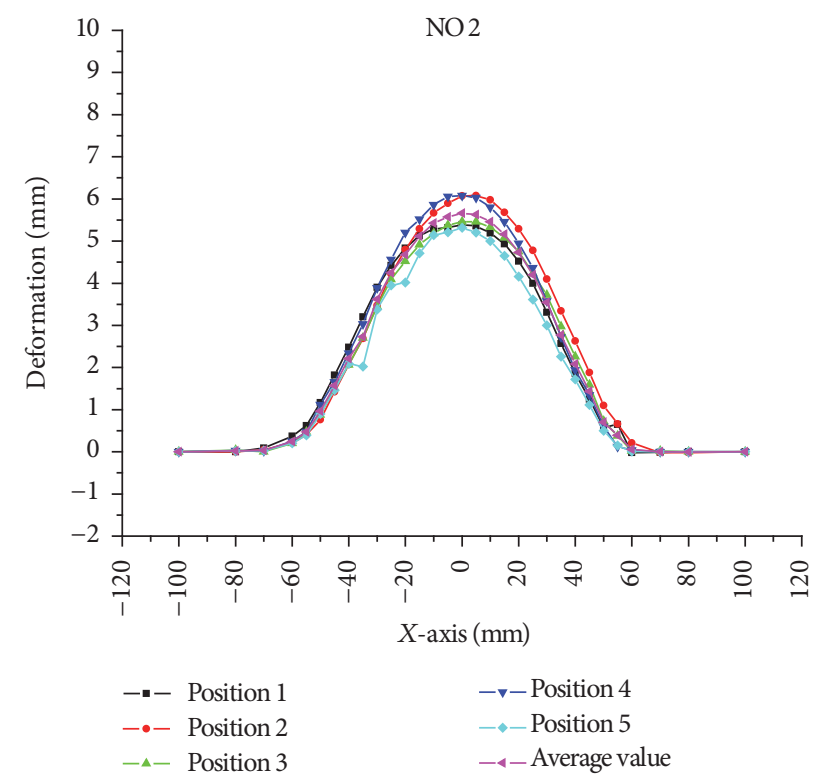

FIgURE 6: Deformation of the tube.

points. Thus, the explosion waves were strengthened on the midcourt lines. Then, the line scars were formed. The line approximately paralleled the axes of the tube.

Six knobs were located inside, and a piece of fragment flew off, as shown in Figures 7(a) and 7(b), which indicated that the tube spalled under the explosive wave. Further observations note that the explosive sect of the tube was incised, as shown in Figures $7(\mathrm{c})$ and $7(\mathrm{~d})$. Figure $7(\mathrm{c})$ indicates the section in the axis direction of the tube. In Figure $7(\mathrm{~d})$, the tube was incised from the initiation annulus. The spall was clearly observed as having a thickness of $4 \mathrm{~mm}$.

The microcharacteristics of the fracture were analyzed by means of SME and a metallographic microscope. Figure 8(a) was the SME photo of the spall fragment in Figure 7(b). The fracture surface was very coarse, which was typical of a ductile fracture. Comparisons between different sampling locations, as shown in Figure 8(b), were conducted: Location 1 was located near the spall crack in the section; Location 2 was between two spall cracks in the section; Location 3 was in the unloaded part of the tube. Figure 8(c) shows the electric metallographic photo in Location 1.

Several cracks were located along the annulus direction. The crystal lattice below the crack tape was obviously distorted, whereas the crystal lattice above the crack tape had minimally changed. The reason may be that the tensile stress manifested on the inner wall and initially acted on the inner part [18-21]. If the tensile stress exceeded the yield stress of the material, the inner part would be drawn and cracked. For the deformation and cracks caused by the energy of tensile stress, the outer material was observed to have an elastic response.

The crystal lattice in Locations 2 and 3, as shown in Figures $8(\mathrm{~d})$ and $8(\mathrm{e})$, depicts the original state. The state of Location 3 out of the explosive region was easily envisioned, whereas the state of Location 2 was unexpected. Analysis suggests that the release of energy in cracks was the main reason.

However, the microscopic observation indicated that the main part of the tube was kept well. The tube still has a certain strength, which meets our engineering needs.

\section{Numerical Simulations}

3.1. Numerical Model. Numerical simulations were conducted to investigate the detailed response of the tube subjected to a cylindrical explosive wave [22, 23]. The commercial software AUTODYN was used to carry out the numerical simulation. The $2 \mathrm{D}$ numerical model was set up on the explosive annulus, considering the symmetry of the experimental model, as shown in Figure 9. The air and TNT were modeled through the Euler solver. Steel was selected as the material of the tube, which was modeled by the Lagrange solver. The boundary condition of Flow_Out was applicable to the Euler grid. The mesh size was kept in $1 \times 1 \mathrm{~mm}$ for AIR, RDX, and STEEL, and the numbers of elements were $200 \times 200=40000,5 \times 400=2000$, and $12 \times 400=$ 4800 , respectively. The mesh size of PETN was $0.25 \times 1 \mathrm{~mm}$, and the amount of elements was $2 \times 400=800$. The ten initiating points were uniformly distributed on the charge. Three arrangers of gauge points were set, respectively, under the initiating point (Gauges 1-5), in the middle line of two nearby initiating points (Gauges 6-10), and between the two arrangers (Gauges 11-15).

The ideal air was selected, and the state equation was written as

$$
P=(\gamma-1) \rho e
$$

where $P$ was the pressure, specific heat $\gamma=1.4$, original density $\rho=1.29 \mathrm{~kg} / \mathrm{m}^{3}$, and specific energy $e=2.5 \times$ $10^{2} \mathrm{~kJ} / \mathrm{m}^{3}$.

The state equation of charge was JWL, expressed as

$$
\begin{aligned}
P= & \alpha\left(1-\frac{\omega}{R_{1} V}\right) \exp \left(-R_{1} V\right) \\
& +\beta\left(1-\frac{\omega}{R_{2} V}\right) \exp \left(-R_{2} V\right)+\frac{\omega E}{V},
\end{aligned}
$$

where $P$ is pressure, $E$ is specific energy, $V=v / v_{0}$ is the specific volume ratio between the explosive production and charge, and $\alpha, \beta, R_{1}, R_{2}, \omega$ were constants calibrated by experimental data. The parameters were shown in Table 2. The data refers to the AUTODYN's material library.

Steel 4340 was selected as the tube material. The density was $\rho=7.83 \cdot 10^{3} \mathrm{~kg} / \mathrm{m}^{3}$. Linear state equation, $\mathrm{J}-\mathrm{C}$ Strength Model, and Grady Failure Model were selected. The parameters of the material model were shown in Table 3 . The data refers to the AUTODYN's material library.

\subsection{Numerical Results and Analysis}

3.2.1. Explosive Wave. The pressure isograms of the tubeloaded explosion were shown in Figure 10. In the beginning, the pressure isograms were centralized near the initiating 


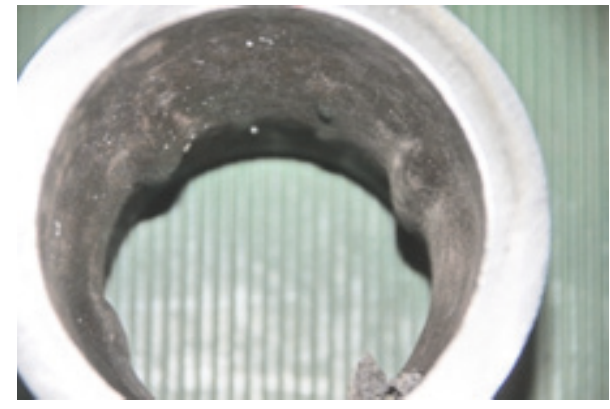

(a) Inner face

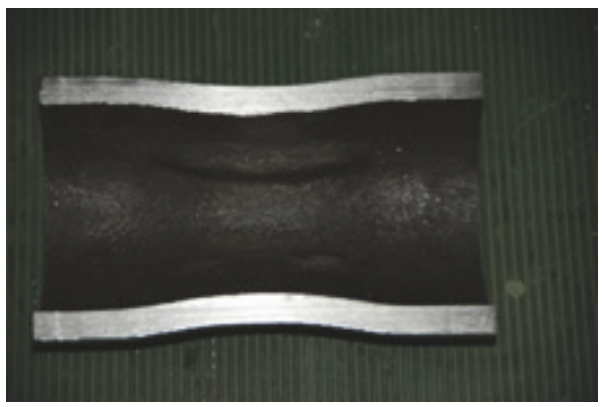

(c) $1 / 2$ section in axis direction

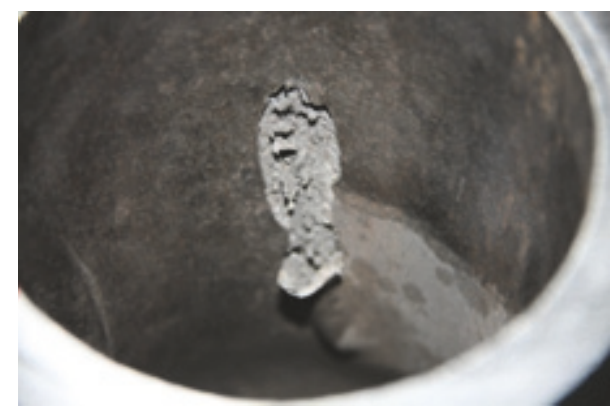

(b) Spall fragment

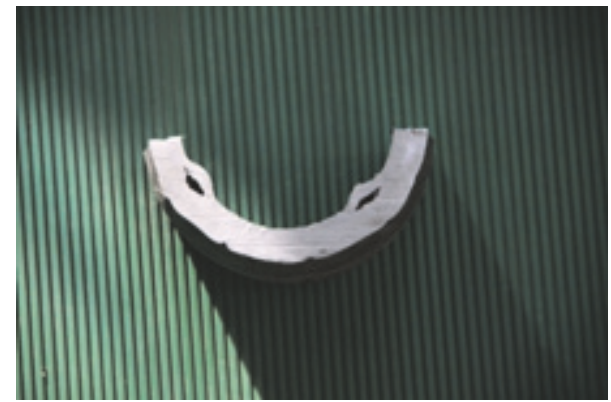

(d) Cross section

Figure 7: Fracture of the tube.

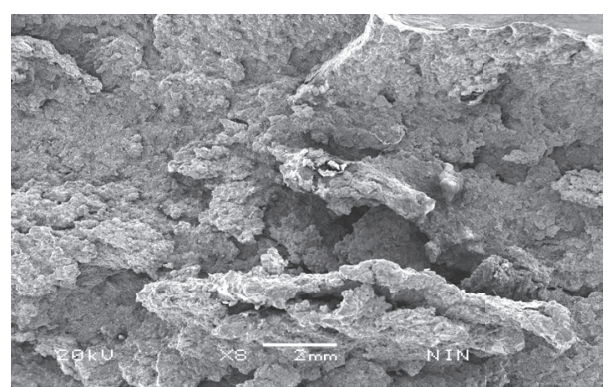

(a) SEM photo of spall fragment

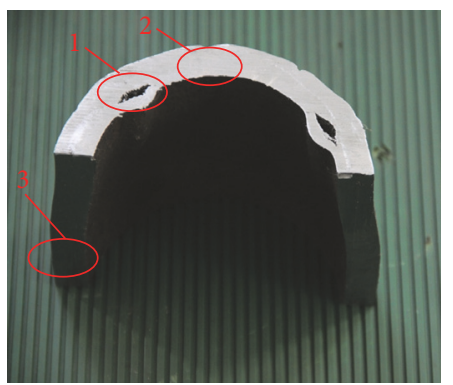

(b) Sampling location

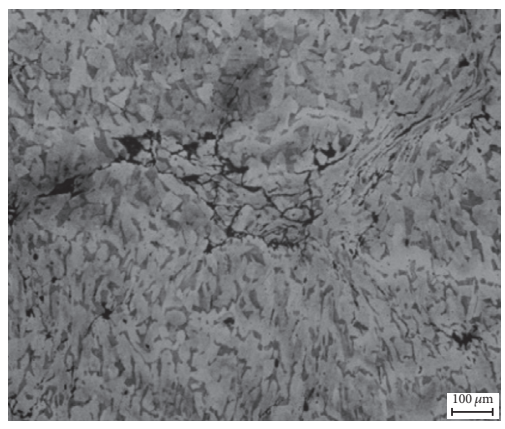

(c) Metallographic photo in Location 1

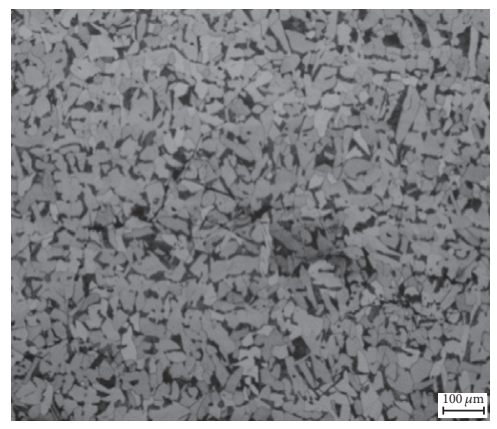

(d) Metallographic photo in Location 2

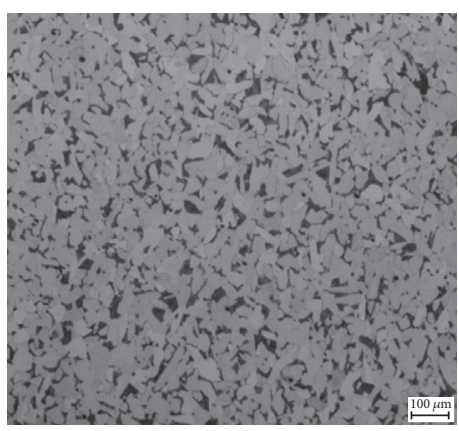

(e) Metallographic photo in Location 3

FIGURE 8: Microcosmic characteristic of fracture.

TABLE 2: Parameters of charges.

\begin{tabular}{lccccccccc}
\hline Parameters & $\rho_{0} /\left(\mathrm{g} / \mathrm{cm}^{3}\right)$ & $P_{\mathrm{cj}} / \mathrm{GPa}$ & $D / \mathrm{km} / \mathrm{s}$ & $E_{0} /\left(\mathrm{GJ} / \mathrm{m}^{3}\right)$ & $\alpha / \mathrm{GPa}$ & $\beta / \mathrm{GPa}$ & $R_{1}$ & $R_{2}$ & $\omega$ \\
\hline PETN & 1.5 & 22.0 & 7.45 & 8.56 & 625.3 & 23.29 & 5.25 & 1.60 & 0.28 \\
RDX & 1.9 & 29 & 7.6 & 6.9 & 520.6 & 53.26 & 4.1 & 1.2 & 0.35
\end{tabular}



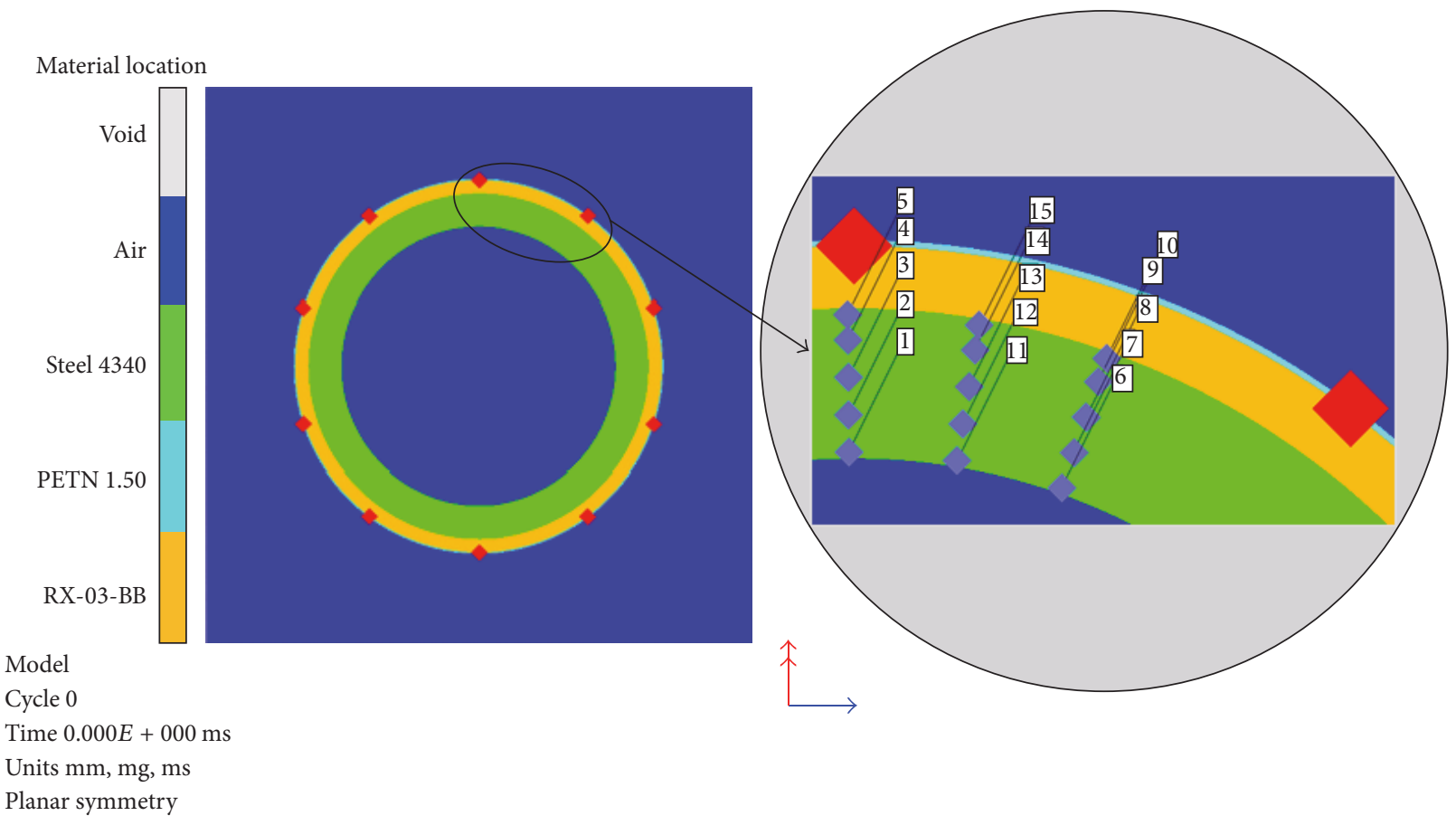

Figure 9: Numerical model.

TABLE 3: Material model of tube.

\begin{tabular}{lcc}
\hline \multicolumn{3}{c}{ Linear state equation } \\
\hline Bulk modulus & $K(\mathrm{GPa})$ & 159.8 \\
Reference temperature & $T(\mathrm{~K})$ & 300 \\
Specific heat & $K_{2}(\mathrm{~J} / \mathrm{kgK})$ & 477.0 \\
\hline \multicolumn{3}{c}{ Strength model $(\mathrm{J}-\mathrm{C})$} \\
\hline Shear modulus & $G_{0}(\mathrm{GPa})$ & 770 \\
Yield stress & $\mathrm{A}(\mathrm{MPa})$ & 790 \\
Hardening constant & $B(\mathrm{MPa})$ & 510 \\
Hardening exponent & $n$ & 0.26 \\
Strain rate constant & $\mathrm{C}$ & 0.014 \\
Thermal softening exponent & $m$ & 1.03 \\
Melting temperature & $T_{\text {melt }}(\mathrm{K})$ & 1793 \\
\hline \multicolumn{2}{c}{ Failure model (Grady spall mode) } \\
\hline Grady spall model & $\mathcal{E}_{c}$ & 0.15 \\
\hline
\end{tabular}

points and spread as the detonation took place. In $3.41 \times$ $10^{-3} \mathrm{~ms}$, the explosive waves collided in the middle of initiating points, thus forming the higher-pressure area. For the thin flake-like charge, the detonating time in the radial direction could be neglected. The collision of explosive waves could be considered as a normal collision. The shock wave parameters on both sides of the collision interface were the same except that they spread in the opposite direction. In a simple analysis, the collision process of the two shock waves can be considered as the normal reflection of the shock wave on a rigid wall. When the isentropic exponent was 3, the pressure of the collision region was 2.39 times greater than the pressure before the collision. Generally, the method of multipoint initiation brought on the asymmetry of the loading time. The collision of explosive waves resulted in the asymmetry of the loading intensity.

Figure 11 depicts the pressure on the exterior of the tube. Gauge 5 was assigned to the initiating point, Gauge 10 on the collision region, and Gauge 15 on the middle of Gauges 5 and 10 , respectively. The pressure of Gauges 5 and 15 was at $9.7 \mathrm{GPa}$ and $8.7 \mathrm{GPa}$, respectively, and was observed to have a small difference. The pressure of Gauge 10 was $13.4 \mathrm{GPa}$, which was higher than the value for the initiating point but was less than the academic estimate, which was 2.39 times greater than the pressure before the collision (Gauges 5 and 15) as the previous analysis. The difference may come from the precision of the calculated grid. A high-precision calculated grid was needed to determine an exact detonation pressure.

The explosive wave of flake-like charges was approximated to a triangular wave. After being reflected on the inner wall, the compression wave would convert to tensile stress, as depicted in Figure 12. In $4.62 \times 10^{-3} \mathrm{~ms}$, tensile stress first appeared in the region under the initiating point, which was approximately $2.89 \mathrm{GPa}$. In $6.09 \times 10^{-3} \mathrm{~ms}$, the collision region suffered tensile stress. The peak value was about $-3.69 \mathrm{GPa}$.

Figure 13 shows the pressure curves of Gauges 2, 7, and 12. The curve depicts that the tube suffered the process of subsequent tensile compression. The signals of Gauges 2 and 12 were unabridged. The pressure gradually regressed to zero after two considerable vibration cycles. The signal of Gauge 7 was interrupted in $6.03 \times 10^{-3} \mathrm{~ms}$, to indicate the gauge point that was damaged by tensile stress. 


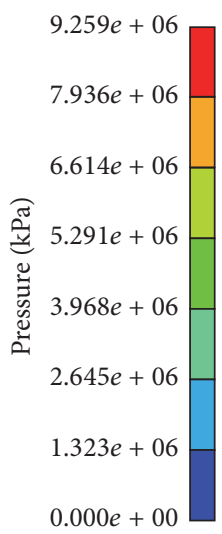

Cycle 11

Time 6.254E - $004 \mathrm{~ms}$

Units $\mathrm{mm}, \mathrm{mg}$, ms

Planar symmetry
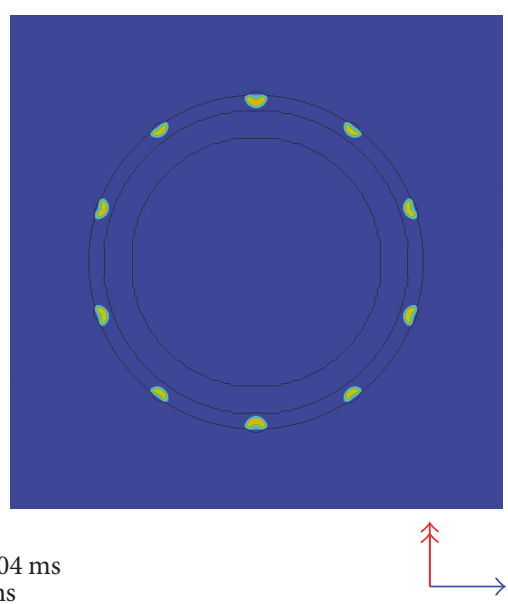

(a) Initiate

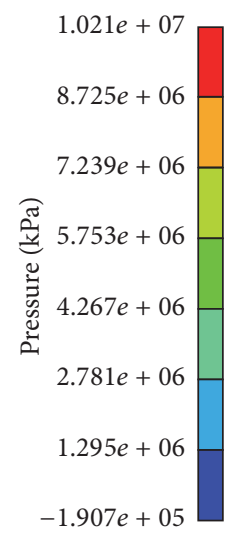

Cycle 22

Time $1.089 E-003 \mathrm{~ms}$

Units $\mathrm{mm}, \mathrm{mg}$, $\mathrm{ms}$

Planar symmetry

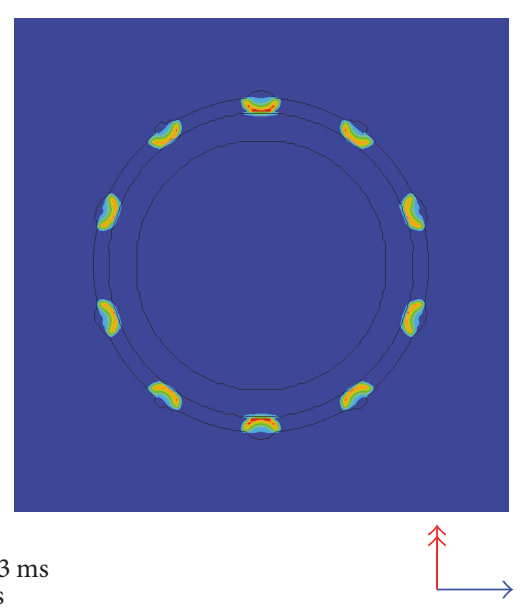

(b) Spread

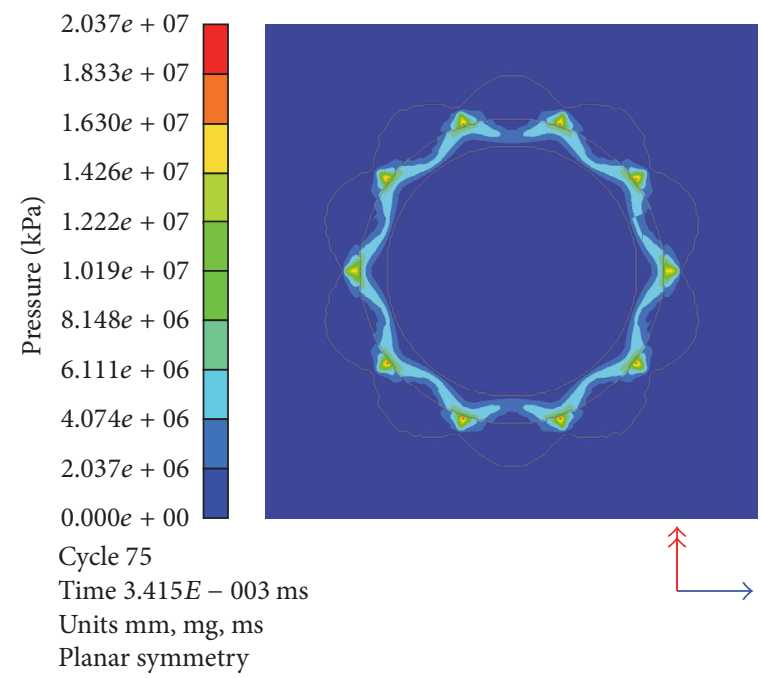

(c) Collide

FIgURE 10: Pressure isograms of tube.

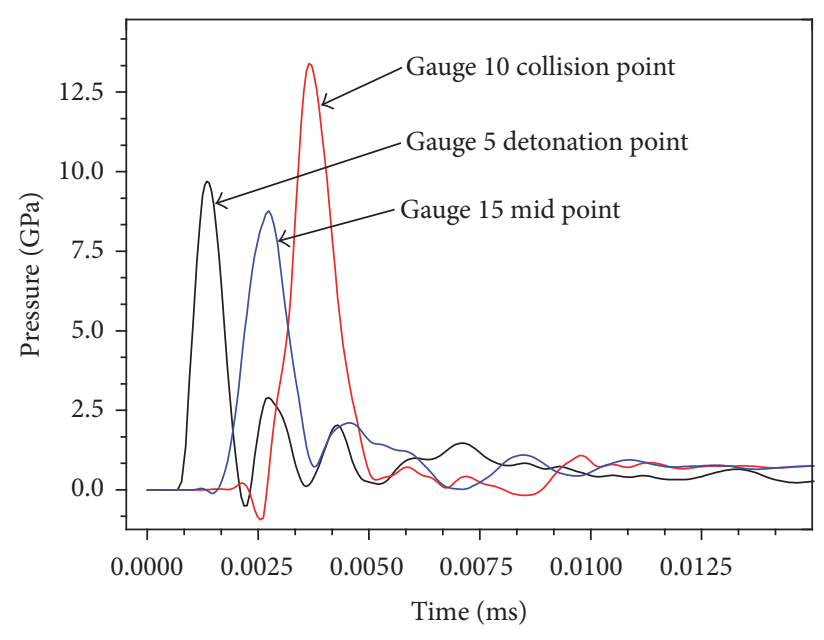

FIGURE 11: Pressure on exterior of tube.
3.2.2. Deformation and Fracture. Figure 14 depicts the state of the tube under explosive loading. In this study, the Grade spall mode was adopted to investigate the fracture, assuming a critical strain of 0.15 . At $6.03 \times 10^{-3} \mathrm{~ms}$, the tube spalled in the collision region, and the cracks increased with tensile stress. Comparisons were done between the numerical analysis and the experiment. The number of spall cracks of the experiment was 6 , the thickness of spall was about $4 \mathrm{~mm}$, and the width and length of the cracks were about $3 \mathrm{~mm}$ and $6 \mathrm{~mm}$, respectively, while a total of ten spalls were formed in the numerical analysis, each with a thickness of approximately $6 \mathrm{~mm}$. The width and length of the cracks were about $3 \mathrm{~mm}$ and $6 \mathrm{~mm}$, respectively, too. The results indicated that the shapes of spall were similar, but the amounts were inconsistent.

Analysis showed that the numerical calculation of the material was fully isotropic, and the load was strictly 


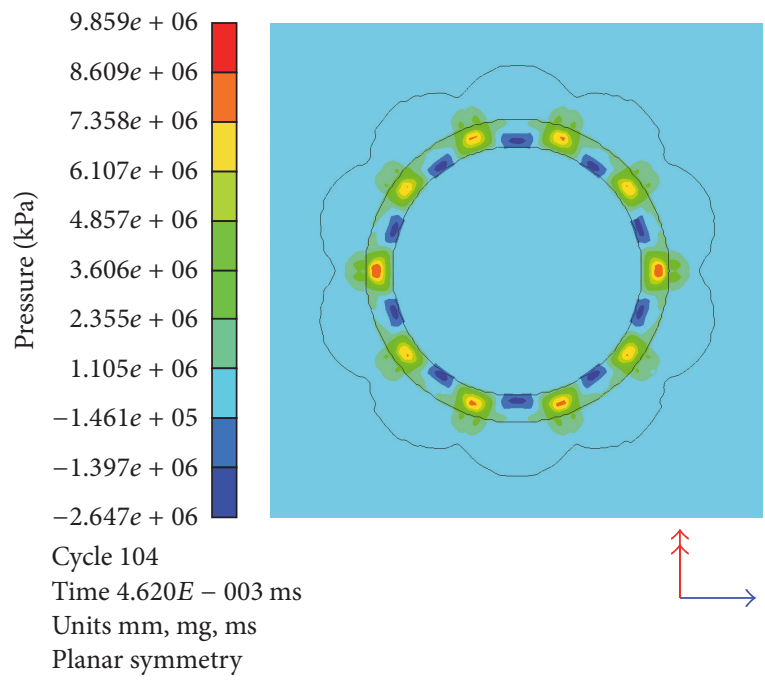

(a)

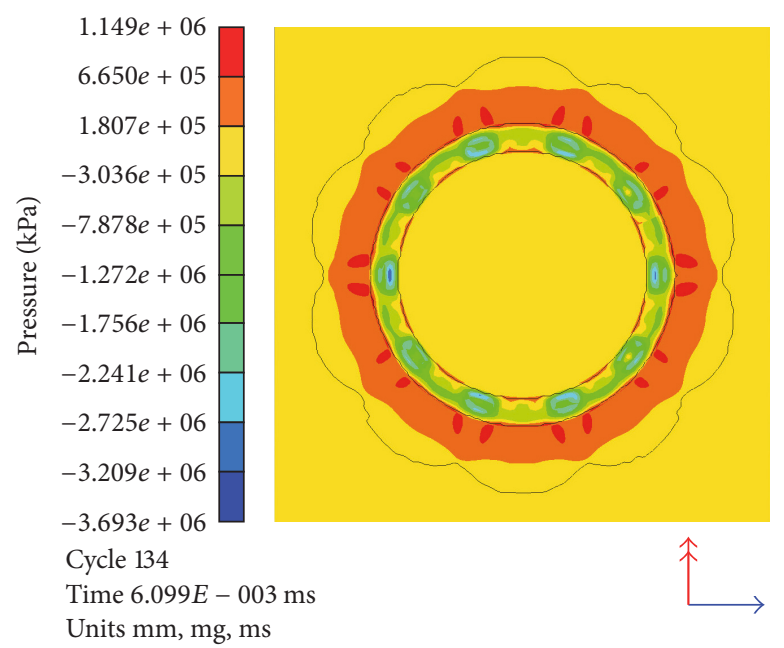

(b)

Figure 12: Tensile stress isograms.

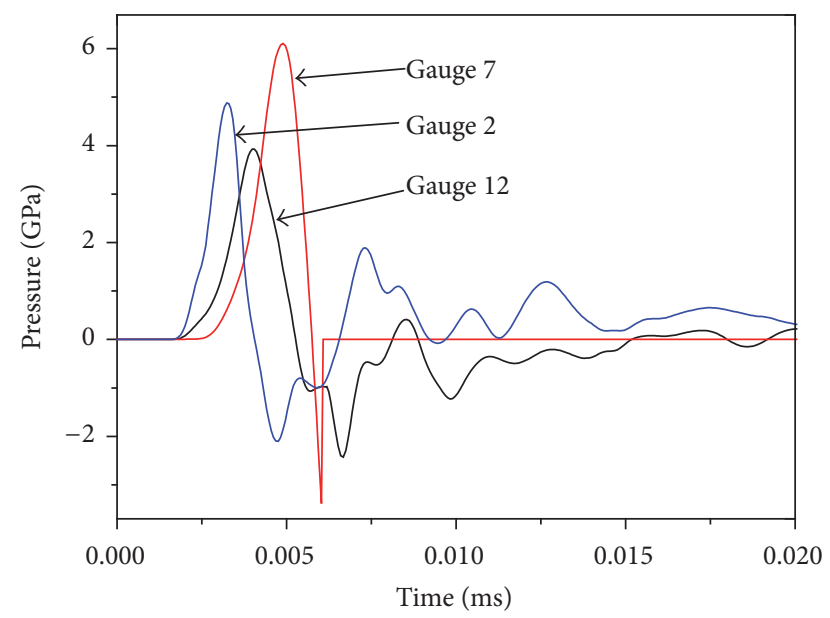

FIgURE 13: Pressure curves of Gauges 2, 7, and 12.

symmetrical. Many factors caused errors in the experiment. The installment of the flake-like charge may be one. The flakelike charges were in millimeter scale. A gap as thin as $1 \mathrm{~mm}$ between charges and tube might bring big scaled distance, which might reduce the peak value of explosive waves in large extent. Additionally, the nonhomogeneity of the material might be a factor. Unavoidable, tiny flaws were observed in the steel. In general, the damage was easy to develop from the flaws.

Figure 15 shows the strain of Gauge 15 on the exterior surface of the tube. The maximum deformation was approximately $-9.9 \%$, which was consistent with experimental results.

From the experimental and numerical results, it can be seen that the damage of the tube can be divided into two parts. The first was the damage on the surface of the tube formed by the contact explosive wave; the second was the damage in the tube wall formed by the tensile stress. The main reason is that the contacted explosive wave is an attenuation pulse loading with very high peak pressure and very short pulse time. In order to reduce the damage of the shell, we can consider reducing the peak pressure and increasing its pulse time, such as setting an air layer or foam material between the charges and the tube.

3.2.3. Velocity. The velocity in the inner wall of the tube was shown in Figure 16. The gauge points were 1, 6, and 11. The peak values of velocity were $252.33 \mathrm{~m} / \mathrm{s}, 370.25 \mathrm{~m} / \mathrm{s}$, and $243.0 \mathrm{~m} / \mathrm{s}$, respectively. The curves of Gauges 1 and 11 were similar, except the response time. Due to the pressure rise caused by the collision of shock waves, the velocity in Gauge 6 in the collision area was larger than others.

From the velocity distribution of the inner wall, it can be seen that the movement of the inner wall was not uniform in time axis and amplitude. The amplitude of velocity in the collision area was significantly large, which indicated that the collision area was where the damage was likely to occur.

\section{Conclusion}

This paper presents the experimental results and numerical simulation of tubes subjected to cylindrical explosive waves.

(1) A flake-like charge and multipoints initiation technique were adopted. Experimental results show that the flake-like charge could be used in high-precision cylindrical explosive loading. The loading method adopted can obtain a certain uniform deformation for the long tube. The microscopic observation indicated that the main part of the tube was kept well. The tube still had a certain strength, which meets out engineering needs.

(2) The method was used in nonstandard machining. However, if the tube is used in a high, inner pressure 


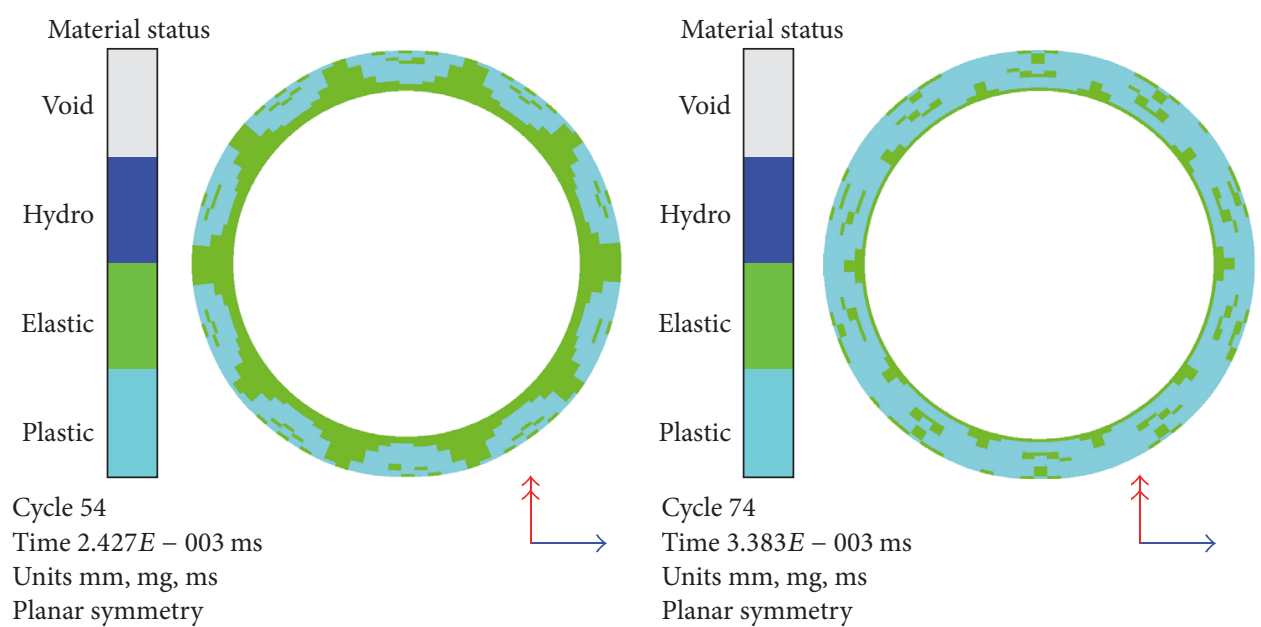

(a)

(b)

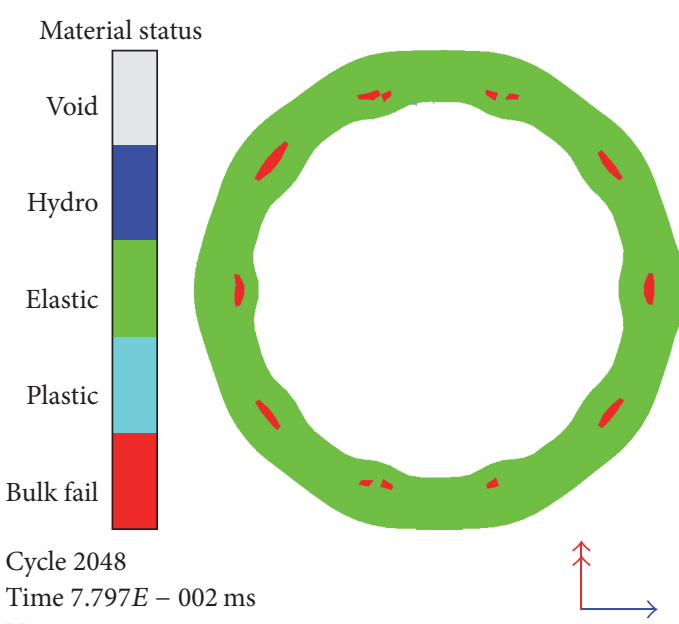

Units $\mathrm{mm}, \mathrm{mg}$, $\mathrm{ms}$

Planar symmetry

(c)

Figure 14: Spall of tube.

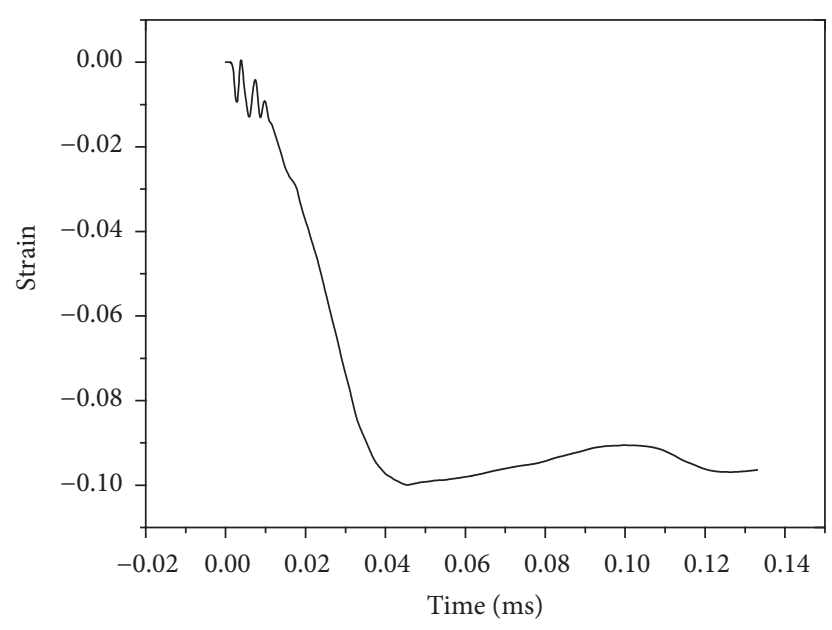

FIGURE 15: Strain of Gauge 15 on the exterior surface.

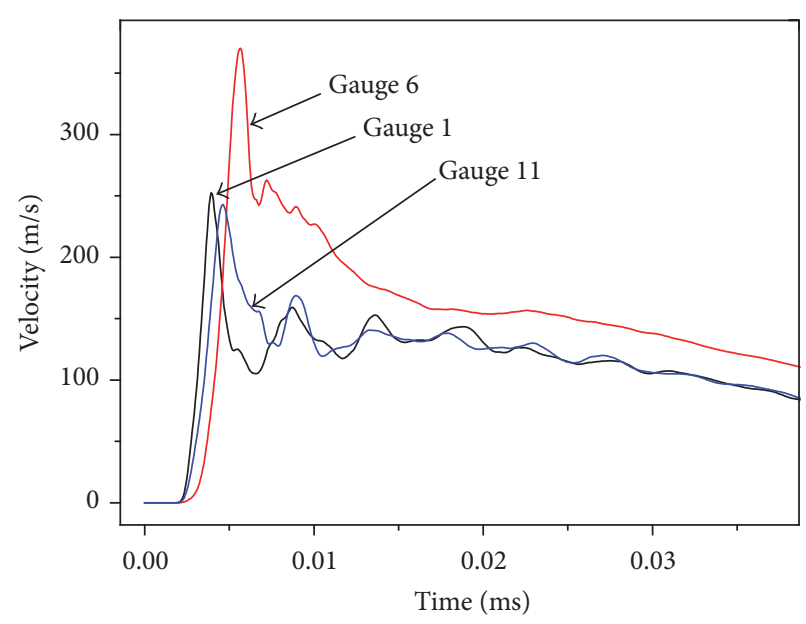

FIGURE 16: Velocity of inner wall. 
condition, the method should be cautiously applied because the loading may bring a change in material characteristics and a partial weakness.

(3) Numerical simulations were conducted to investigate the detailed response of the tube subjected to a cylindrical explosive wave. The results indicate that the collision of explosive waves brought inconsistencies in pressure and velocity. The pressure and velocity in the collision region were significantly higher than those of other parts. So the collision regions were prone to damage. Comparisons were done between the numerical analysis and the experiment. The overall deformation of the tube in the numerical analysis was consistent well with the experimental results. But the damage was not a good match. In the future work, we will work on the experimental technique and the damage model under cylindrical converging shock wave.

\section{Conflicts of Interest}

The authors declare that there are no conflicts of interest regarding the publication of this paper.

\section{References}

[1] J. H. Lee and B. H. K. Lee, "Cylindrical Imploding Shock Waves," Physics of Fluids, vol. 8, no. 12, pp. 2148-2152, 1965.

[2] H. Matsuo, "Converging shock waves generated by instantaneous energy release over cylindrical surfaces," Physics of Fluids, vol. 22, no. 9, pp. 1618-1622, 1979.

[3] J. H. T. Wu, R. A. Neemeh, and P. P. Ostrowski, "Experimental studies of the production of converging cylindrical shock waves," AIAA Journal, vol. 18, no. 1, pp. 47-48, 1980.

[4] N. Apazidis, M. B. Lesser, N. Tillmark, and B. Johansson, "An experimental and theoretical study of converging polygonal shock waves," Shock Waves, vol. 12, no. 1, pp. 39-58, 2002.

[5] Y. E. Krasik, A. Grinenko, A. Sayapin, and V. T. Gurovich, "Generation of sub-Mbar pressure by converging shock waves produced by the underwater electrical explosion of a wire array," Physical Review E, vol. 73, Article ID 057301, 2006.

[6] L. D. Bertholf, L. D. Buxton, B. J. Thorne et al., "Damage in steel plates from hypervelocity impact. II. Numerical results and spall measurement," Journal of Applied Physics, vol. 46, no. 9, pp. 3776-3783, 1975 (Bulgarian).

[7] J. Buchar, S. Rolc, and J. Hrebícek, "Strain rate dependence of the spall strength of steels," Le Journal de Physique IV, vol. 07, no. C3, pp. C3-951-C3-956, 1997.

[8] S. F. Gnyusov, V. P. Rotshtein, A. E. Mayer et al., "Simulation and experimental investigation of the spall fracture of 304L stainless steel irradiated by a nanosecond relativistic highcurrent electron beam," International Journal of Fracture, vol. 199, no. 1, pp. 59-70, 2016.

[9] G. Heilig, N. Durr, M. Sauer, and A. Klomfass, "Mesoscale analysis of sintered metals fragmentation under explosive and subsequent impact loading," Procedia Engineering, vol. 58, pp. 653-662, 2013.

[10] K. Ramajeyathilagam, C. P. Vendhan, and V. Bhujanga Rao, "Experimental and numerical investigations on deformation of cylindrical shell panels to underwater explosion," Shock and Vibration, vol. 8, no. 5, Article ID 798735, pp. 253-270, 2001.

[11] Z. Zhang, F. Ming, and A. Zhang, "Damage characteristics of coated cylindrical shells subjected to underwater contact explosion," Shock and Vibration, vol. 2014, Article ID 763607, 15 pages, 2014.

[12] Y. Du, L. Ma, J. Zheng, F. Zhang, and A. Zhang, "Coupled simulation of explosion-driven fracture of cylindrical shell using SPH-FEM method," International Journal of Pressure Vessels and Piping, pp. 28-35, 2016.

[13] L. Xuemei, "The spall characteristics of cylindrical steel tube under inward explosion loading," Explosion and Shock Waves, vol. 25, pp. 107-111, 2005.

[14] K. Terao, H. Kobayashi, and Z. Dianfeng, "Experimental investigation of cylindrical detonation wave," Journal of Physics Conference Series, vol. 774, no. 1, article 012074, 2016.

[15] E. A. Kozlov and A. V. Petrovtsev, "Cumulation of a spherically converging shock wave in metals and its dependence on elasticplastic properties, phase transitions, spall and shear fractures," Journal of Physics: Conference Series, vol. 490, no. 1, Article ID 012191, 2014.

[16] A. V. Shutov, V. G. Sultanov, and S. V. Dudin, "Mathematical modeling of converging detonation waves at multipoint initiation," Journal of Physics: Conference Series, vol. 774, no. 1, Article ID 012075, 2016.

[17] J. D. Colton, Measurement of Pressure, Impulse and Detonation Velocity for Detasheet L Explosive, 1971.

[18] C. Li, B. Li, J. Y. Huang et al., "Spall damage of a mild carbon steel: effects of peak stress, strain rate and pulse duration," Materials Science and Engineering: A, vol. 660, pp. 139-147, 2016.

[19] M. Mirmomeni, A. Heidarpour, X.-L. Zhao, C. R. Hutchinson, J. A. Packer, and C. Wu, "Fracture behaviour and microstructural evolution of structural mild steel under the multi-hazard loading of high-strain-rate load followed by elevated temperature," Construction and Building Materials, vol. 122, pp. 760-771, 2016.

[20] A. Remennikov, T. Ngo, D. Mohotti, and atal, "Experimental investigation and simplified modeling of response of steel plates subjected to close-in blast loading from spherical liquid explosive charges," International Journal of Impact Engineering, vol. 101, pp. 78-89, 2017.

[21] J. Mescall and R. Papirno, "Spallation in cylinder-plate impact," Experimental Mechanics, vol. 14, no. 7, pp. 257-266, 1974.

[22] F. S. Koslan, M. Z. Othman, A. Mujahid, and A. Zaidi, "Finite element analysis's interrelationship equation to predict the deflection of rolled homogeneous armor steel plate due to explosion based on different explosive masses and plate thicknesses," Modern Applied Science, vol. 9, no. 4, pp. 178-185, 2015.

[23] V. Aune, G. Valsamos, F. Casadei, M. Larcher, M. Langseth, and T. Børvik, "Numerical study on the structural response of blastloaded thin aluminium and steel plates," International Journal of Impact Engineering, vol. 99, pp. 131-144, 2017. 


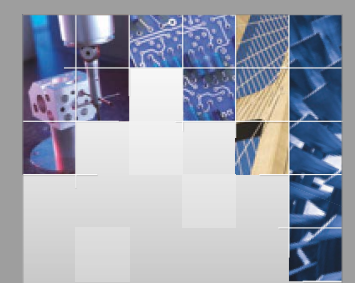

\section{Enfincering}
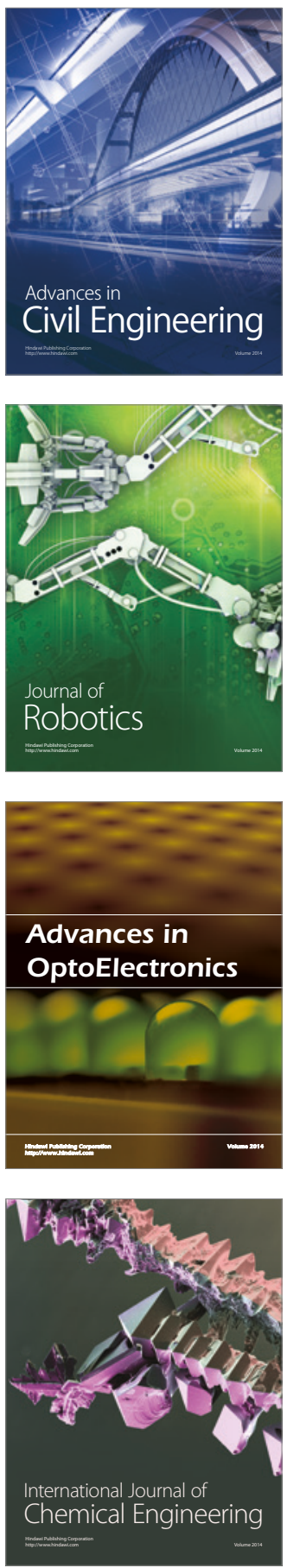

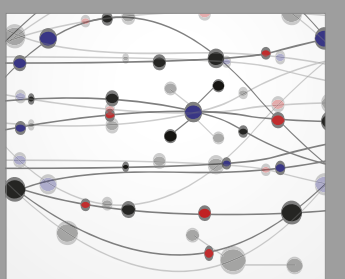

The Scientific World Journal

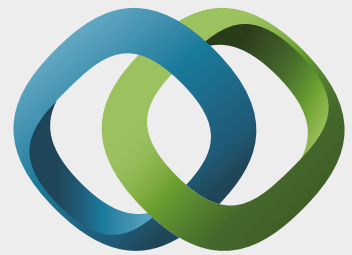

\section{Hindawi}

Submit your manuscripts at

https://www.hindawi.com
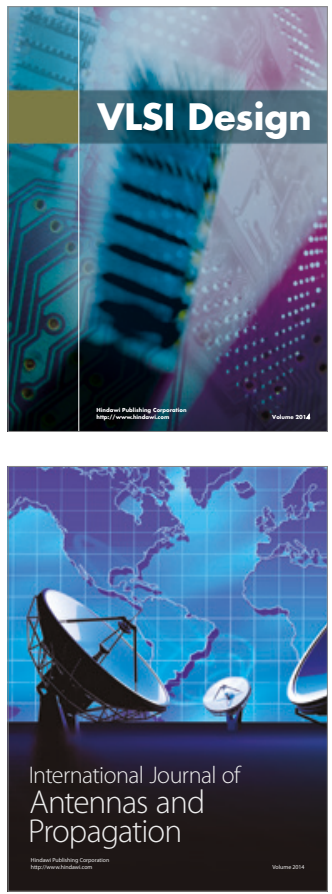

\section{Rotating}

Machinery
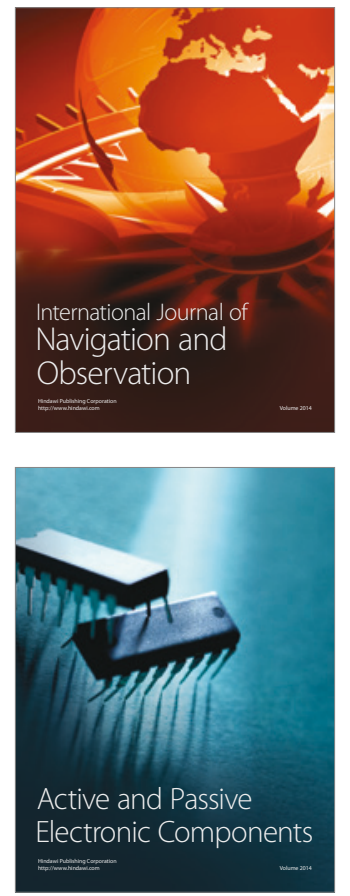
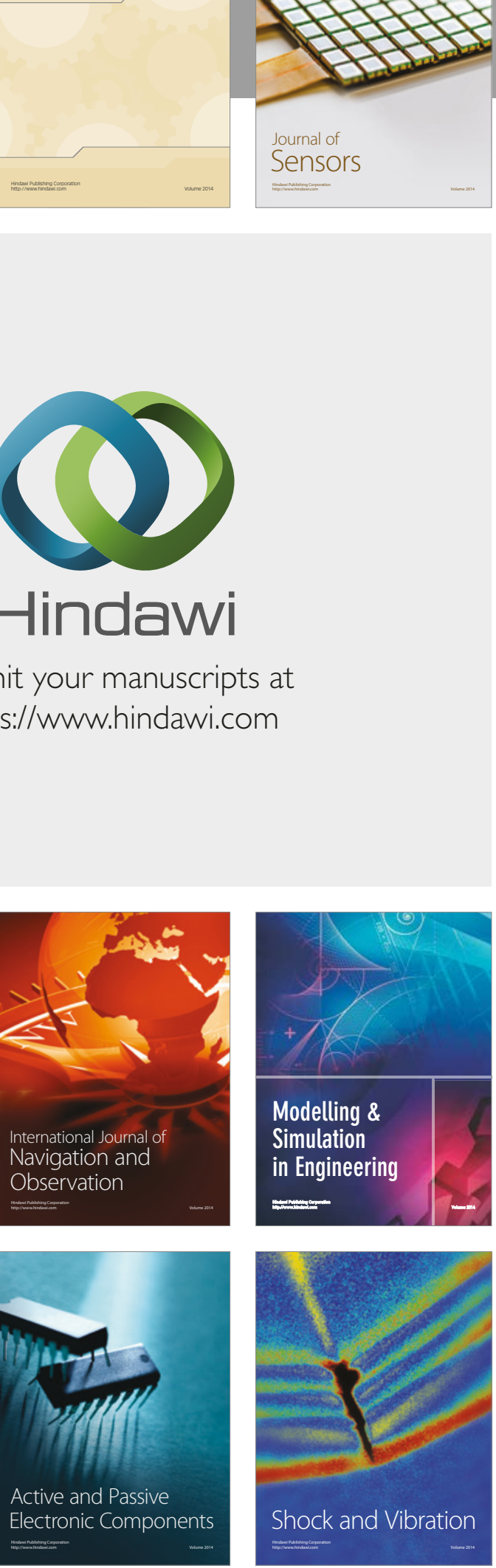
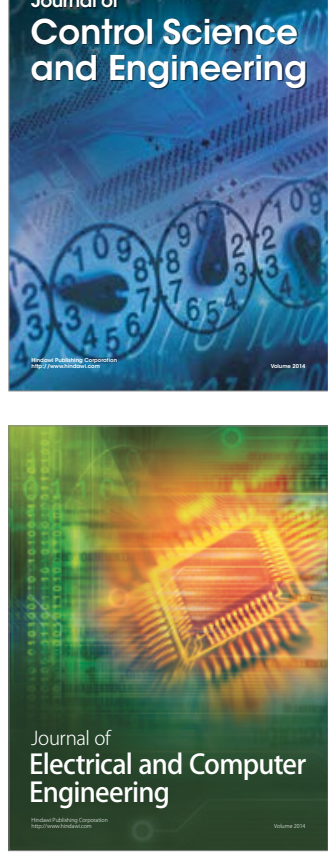

Distributed

Journal of

Control Science

and Engineering
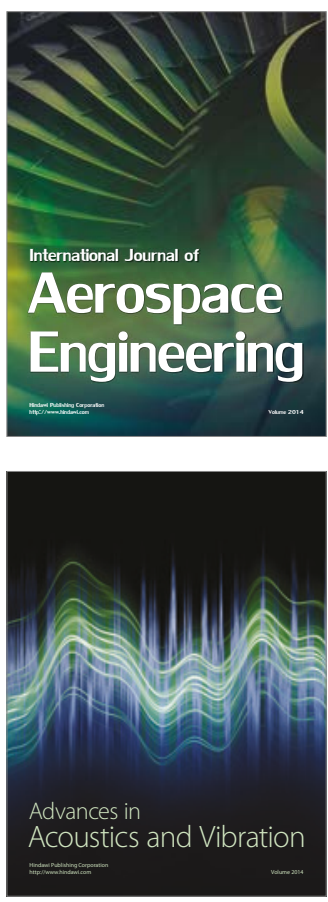

Sensor Networks 